\title{
Carbohydrate knowledge in diabetic emergency department patients at an academic institution
}

\author{
Preeti Dalawari*1, David Sprowls ${ }^{1}$, Vicki Moran ${ }^{2}$, Eric Armbrecht ${ }^{3}$ \\ ${ }^{1}$ Division of Emergency Medicine, Saint Louis University School of Medicine, Saint Louis, Missouri, United States \\ ${ }^{2}$ School of Nursing, Saint Louis, Saint Louis University, Missouri, United States \\ ${ }^{3}$ Saint Louis Center for Outcomes Research, Saint Louis, Missouri, United States
}

Received: December 2, 2016

DOI: $10.5430 /$ jha.v6n2p15
Accepted: January 18, 2017

Online Published: February 15, 2017

\begin{abstract}
Background: Diabetes Mellitus (DM) affects $12.3 \%$ of the U.S. population and is responsible for \$245 billion in annual costs. Knowledge about their disease is an important part of patients' self-management.

Objective: The objective of this study was to describe the baseline level of knowledge of patients with diabetes in this emergency department (ED), including behaviors related to healthy eating such as carbohydrate counting (CC).

Methods: This was a cross sectional interview survey conducted at an academic tertiary center. An 8-item survey was developed to assess areas of diabetes self-care and carbohydrate knowledge. Trained research assistants approached all medically stable, non-pregnant ED patients with a past medical history of diabetes for participation. Descriptive statistics and ANOVA analysis were used.

Results: Of the 115 patients approached, 98 were willing to participate; $54 \%$ were using insulin and $68 \%$ were female. The average age was $55(S D+/-14)$ years and diagnosed for an average of $12(S D+/-10)$ years. Fifty three percent did not check their morning blood sugar. Only $20 \%$ could accurately state the target hemoglobin A1c. While $48 \%$ of participants could relate the importance of carbohydrates to blood sugar, only 5\% could state the number of grams of carbohydrates in a slice of bread. Only 1 participant correctly answered all 4 of the carbohydrate questions. Higher education and more visits with a nutritionist were associated with carbohydrate knowledge.

Conclusions: Carbohydrate knowledge among this ED population was poor. Opportunities exist for patient education.
\end{abstract}

Key Words: Diabetes knowledge, Carbohydrate knowledge, Emergency department patient, Diabetes self-management education and training

\section{INTRODUCTION}

Diabetes has become one of the fastest growing health epidemics in the U.S. According to the Centers for Disease Control and Prevention, diabetes currently affects 29 million individuals or 12.3 percent of the US population over the age of 20 , with $3.5 \%$ being undiagnosed. This statistic consists of 1.7 million people ages 20 years or older newly diagnosed in 2012 alone. The financial burden to treat the disease is just as staggering with diabetes responsible for $\$ 245$ billion in direct and indirect costs in the U.S. in 2012. ${ }^{[1]}$ Diabetes a commonly encountered diagnosis in the emergency department (ED), accounting for $9.4 \%$ of all adult ED visits. ${ }^{[2]}$ Using the National Hospital Ambulatory Medical Care Survey (NHAMCS) data, Asao et al. noted that diabetes among

\footnotetext{
*Correspondence: Preeti Dalawari; Email: pdalawar@slu.edu; Address: School of Medicine Division of Emergency Medicine, 3635 Vista at Grand Avenue, First Floor Desloge Towers, Saint Louis, Missouri 63110, United States.
} 
patients visiting the EDs, diabetes related hospitalizations, and diabetes related deaths are likely underreported. ${ }^{[1,3]}$ Diabetes is often missed when a patient makes an ED visit, and may have indirectly affected the ED visits. ${ }^{[3]}$ A study by Menchine et al. noted a $14 \%$ undiagnosed diabetes prevalence rate and $42 \%$ suboptimal glycemic control for those with known diabetes at their urban ED. ${ }^{[4]}$

Numerous studies indicate that better glycemic control, determined by glycosylated hemoglobin A1c (Hb A1c), reduces the risk of microvascular and macrovascular complications. ${ }^{[5-9]}$ Precision and knowledge with carbohydrate counting (CC), as well as health literacy is associated with lower A1c values. ${ }^{[9-15]}$ Studies, mostly from primary care settings, have shown low knowledge about diabetes and general health, contribute to poorer diabetic outcomes. ${ }^{[9,12,14]}$

Diabetes self-management education and training (DSME), supported by the American Diabetes Association as well as the American Association of Clinical Endocrinologists, is a critical component of care for people with diabetes. ${ }^{[16]}$ The National Standards for Diabetes Self-Management Education and Support define DSME as an ongoing process to facilitate the knowledge, skills, and abilities needed for diabetic self-care by DSME trained providers (i.e. diabetic educator such as a registered nurse, nutritionist, etcetera). ${ }^{[17]}$ The seven key areas that self-care focus on include healthy eating, being active, monitoring blood sugars, medication adherence, problem solving for diabetes control, healthy coping, and reducing risks of complications. ${ }^{[18]}$ While healthy eating incorporates many aspects, $\mathrm{CC}$ is one of the tools that may be needed, depending on an individual's goals. ${ }^{\text {[9] }}$ The approach used in diabetes education is not only education of the patient but also the integration of techniques that promote effective self-management, such as goal setting and follow up. ${ }^{[18,19]}$ Currently, only $6.8 \%$ of privately insured people newly diagnosed with diabetes in the United States received DSME within the first 12 months. The age adjusted proportion of diabetic adults having ever attended a diabetes education class is just $57 \%$. $^{[19]}$

The objective of this study was to describe the baseline level of knowledge of patients with diabetes in this ED, including behaviors related to healthy eating such as CC.

\section{MethodS}

\subsection{Study design}

This was a cross sectional interview survey study of a convenience sample of adults presenting to an urban, academic emergency department during a four-week timeframe.

\subsection{Study setting and population}

This study was conducted at a Level I trauma and tertiary care referral center in the Midwest with an annual volume of approximately 36,000 and admission rate of $30 \%$. The center is located in an urban area with a racial/ethnic mix of African American (50\%), Caucasian (46\%), and other (4\%) and a poverty rate of $27.8 \%$ as defined by the federal poverty level. ${ }^{[20]}$ The prevalence of diabetes within the state counties served by the institution varies from $10.9 \%-11.5 \%$. ${ }^{[21]}$ All surveys were administered in December 2011. After an initial medical screening to assess acuity and history of insulin dependent or non-dependent Diabetes Mellitus (DM), patients age 18 years and older who self-reported the ability to read, write, and understand English were invited to participate. Exclusion criteria included the critically ill, acute psychiatric conditions (such as homicidal/suicidal ideation), altered mental status from any cause, language barriers, or attending physician discretion. All participants provided verbal consent. Survey responses were anonymous. The Institutional Review Board of the university approved the study.

\subsection{Survey content and administration}

Due to the fast paced nature of the ED, a novel 8 item survey with the lowest possible reading grade level was developed to assess participants' health knowledge about diabetes. The authors developed the survey with specific guidance from one author (EA) with 14 years of experience in diabetes self-management education research and community-based health programs. Demographic information included age, gender, years as a diabetic, diabetic medications, use of a diabetic educator or nutritionist, and reason for ED visit. Participants were also asked about their most recent morning blood sugar results. The first four questions (identifying symptoms of hyperglycemia, normal hemoglobin A1c level [Hb A1c], normal blood sugar range, and importance of selffoot exam) were adapted from a validated survey, the Spoken Knowledge in Low Literacy in Diabetes Scale (SKILLD). ${ }^{[2]}$ In order to determine knowledge regarding carbohydrates and diabetes, participants were asked what a carbohydrate is (or an example), why carbohydrates are important to diabetics, how many carbohydrates should be eaten in a single meal, and how many carbohydrates are in a slice of bread. Before the study began, a draft version of the survey was tested by interviewing 14 people with diabetes who attended a community forum for diabetes education and support. The interviews focused on respondent understanding of items, word choices, challenges with administration and suggestions for improvement. The draft survey was revised based on feedback, which improved the instrument's readability and content validity. The revised survey has a Flesch-Kincaid 
grade level of 4.7 .

The survey was administered by trained research associates (e.g., medical students) between the hours of 8 a.m. to 5 p.m. on a convenience sample of weekdays and weekends. Research associates identified potential participants through the computerized tracking system as well as discussion with ED staff, and approached patients after the initial evaluation by a physician.

A key of correct and possible incorrect answers was created prior to the start of the survey. When a respondent's answers were not addressed by the key, such exceptions were handled by discussion of two or more qualified researchers to reach consensus about the correctness of the response. For this study, items were either correct or incorrect for the purposes of scoring; missing answers or responses such as "I don't know" were considered incorrect. Partial credit was not given. While this approach to scoring likely results in lower measurements of patient knowledge, it was consistently applied across participants.

All data were analyzed using the Statistical Package for the Social Sciences, version 19.0 (SPSS Inc., Chicago, IL). The demographic and medical history characteristics of the sample were reported with the percent correct for each item of the knowledge assessment of the survey. A total knowledge score (range 0 to 4 ) related to nutritional knowledge about carbohydrate was created by summing the correct scores across the 4 related items, yielding a possible range of 0 (none correct) to 4 (all correct). The association between the total carbohydrate knowledge score and selected respondent attributes (i.e., insulin use, gender, years of diabetes, and education, frequency of visits with a nutritionist) was measured with ANOVA. Years of diabetes were recoded from a continuous variable to a categorical one with 4 levels (1-5 years, 6-10 years, 11-19 years, and 20+ years); frequency of visits with a nutritionist/diabetes educator was also recoded from a continuous variable to a categorical one ( 0 visits, $1-2$ visits, 3-9 visits, 10+ visits). Two respondents who reported that had seen a nutritionist but could not recall the number of visits was classified as having 1-2 visits for the purpose of the analysis. An alpha of 0.05 was deemed statistically significant on a two-tail test. In addition, a logistic regression model was developed to measure the association between carbohydrate knowledge (defined as a total score of 2 or more) and frequency of visits with a nutritionist, while controlling for educational level of the participant. Odds ratios with $95 \%$ confidence intervals were reported for the included variables.

\section{Results}

A total of 115 patients were approached; 98 were willing to participate.
Table 1. Demographics of sample population $(\mathrm{n}=98)$

\begin{tabular}{|c|c|}
\hline Demographic Items & Valid, n (\%) \\
\hline \multicolumn{2}{|l|}{ Gender } \\
\hline - Male & $31(31.6)$ \\
\hline - Female & $67(68.4)$ \\
\hline $\operatorname{Age}(S D)$ & $55(14)$ \\
\hline \multicolumn{2}{|l|}{ Education Level } \\
\hline - Less than high school & $35(35.7)$ \\
\hline - High school/GED & $38(38.8)$ \\
\hline - $\quad$ Some college & $19(19.4)$ \\
\hline - $\quad$ College completion & $6(6.1)$ \\
\hline Years as diabetic $(S D)$ & $12(10)$ \\
\hline \multicolumn{2}{|l|}{ Insurance } \\
\hline - $\quad$ Private & $26(26.5)$ \\
\hline - $\quad$ Medicaid & $20(20.4)$ \\
\hline - $\quad$ Medicare & $20(20.4)$ \\
\hline - $\quad$ Medicaid and Medicare & $21(21.4)$ \\
\hline - None & $11(11.2)$ \\
\hline \multicolumn{2}{|l|}{ Insulin Use } \\
\hline - Yes & $53(54.1)$ \\
\hline$\bullet \quad$ No & $45(45.9)$ \\
\hline \multicolumn{2}{|c|}{ Meeting with Nutritionist/Diabetes Educator } \\
\hline - Yes & $68(69.4)$ \\
\hline - $\quad$ No & $30(30.6)$ \\
\hline
\end{tabular}

Note. GED: General Educational Development

As shown in Table 1, the majority of the sample was female, had some form of insurance, and had met with a diabetic educator/nutritionist at some point since their diagnosis. The participants reported a variety of complaints as reasons to be seen in the ED including chest pain (13\%), shortness of breath $(12 \%)$, and head pain (12\%). Only seven patients presented for hyperglycemia. Fifty-three participants stated they took pills for their diabetes but only 29 knew the name of their diabetes medication. Fifty-two participants stated that they did not check their blood sugar in the morning. Of those who did, the average self-reported blood sugar was 147 (range 40-456). Of those using insulin $(n=53)$, only twenty nine checked their morning blood sugar.

Table 2 shows the percentage correct of the knowledge questions. While more than half of the participants knew some symptoms of hyperglycemia, normal blood sugar range, and what to look for on a self-exam of the foot, less than half were aware of the normal $\mathrm{Hb} \mathrm{A} 1 \mathrm{c}$ level or the answers to the carbohydrate focused questions.

Table 3 lists the total score of carbohydrate knowledge by important demographic factors. The logistic regression model showed that controlling for education, those who had more visits with a nutritionist were 1.7 times more likely to have some knowledge. 
Table 2. Percent correct of all knowledge questions $(n=98)$

\begin{tabular}{lll}
\hline Questions & Percent Correct $(\mathbf{n})$ & $\mathbf{9 5 \%}$ CI \\
\hline Symptoms of hyperglycemia & $66.3 \%(65)$ & $(56.8,75.9)$ \\
Hemoglobin Alc Target & $20.4 \%(20)$ & $(12.3,28.5)$ \\
Normal blood sugar range & $69.4 \%(68)$ & $(60.0,78.7)$ \\
Foot exam purpose & $75.5 \%(74)$ & $(66.8,84.2)$ \\
Carbohydrate Focused & & $(37.9,58.0)$ \\
$\bullet \quad$ Definition/example & $48.0 \%(47)$ & $(34.9,54.9)$ \\
• Importance to diabetics & $44.9 \%(44)$ & $(6.7,9.5)$ \\
- Number in bread & $5.1 \%(5)$ & $(8.9,23.8)$ \\
All 4 answers correct & $16.3 \%(16)$ & \\
\hline
\end{tabular}

Table 3. Total carbohydrate knowledge score by selected patient characteristics $(\mathrm{n}=98)$

\begin{tabular}{|c|c|c|}
\hline Demographic Items & $\begin{array}{l}\text { Total Score } \\
(\text { mean, } S D)\end{array}$ & $p$-value \\
\hline Gender & & .37 \\
\hline - Male & $1.0(0.9)$ & \\
\hline - Female & $1.2(1.1)$ & \\
\hline Insulin Use & & .891 \\
\hline - $\quad$ Yes & $1.2(1.0)$ & \\
\hline - $\quad$ No & $1.1(1.0)$ & \\
\hline Education Level & & .002 \\
\hline - $\quad$ Less than high school & $0.8(1.0)$ & \\
\hline • $\quad$ High school/GED & $1.1(1.0)$ & \\
\hline - Some college & $1.5(0.9)$ & \\
\hline - College degree & $2.3(1.0)$ & \\
\hline Nutritionist Visits & & .001 \\
\hline$\bullet \quad 0$ & $0.7(0.9)$ & \\
\hline - $1-2$ & $1.2(1.0)$ & \\
\hline - $\quad 3-9$ & $1.0(1.0)$ & \\
\hline • $10+$ & $1.9(1.1)$ & \\
\hline Years as diabetic $(S D)$ & & .884 \\
\hline - $1-5$ & $1.1(1.0)$ & \\
\hline - $6-10$ & $1.2(1.1)$ & \\
\hline - $\quad 11-19$ & $1.0(1.0)$ & \\
\hline - $\quad 20+$ & $1.3(1.2)$ & \\
\hline
\end{tabular}

Note. ${ }^{*}$ Total score is from 0 (no questions correct) to 4 (all questions correct); GED: General Educational Development

\section{Limitations}

As a descriptive survey, the attempt was to measure the knowledge of the patient with diabetes. Cross-sectional survey designs have inherent limitations including recall bias and potential instrument related issues such as validity. Therefore, measures were taken to strengthen face and content validity as described in the methods sections.

The use of a single, urban emergency department may not be representative of other health care centers, or emergency departments serving a different subset of patient. The sur- vey was a convenience sample conducted during times when the research assistant was available to enroll patients, and certain members of the patient population declined to participate in the survey. Both of these may add to selection bias, although screening was consecutive when a research assistant was available. The type of diabetes was not asked or recorded in this study, as many patients are not aware of this classification. Insulin use was used as a proxy for insulin dependent although this may not necessarily be the case, and adjustments of daily insulin dosing cannot be assumed. An actual Hgb A1c was not ordered to look for a correlation between knowledge and glycemic control.

Finally, health literacy was not tested in this cohort with one ED systematic review showing a collective health literacy level at or below an eighth grade level for $40 \%$ of ED patients. ${ }^{[23]}$ However, education may be used as a proxy as studies note limited education is associated with limited health literacy. ${ }^{[24,25]}$ We also noted higher education to be associated with greater knowledge.

\section{DiscuSSION}

Overall, knowledge regarding carbohydrates and its relationship to diabetes, as well as $\mathrm{Hb} \mathrm{A} 1 \mathrm{c}$ testing, was poorly understood in this cohort. Participants were more knowledgeable about other self-care behaviors such as foot exam, symptoms of hyperglycemia, and normal blood sugar range. Only one person, who had diabetes for over 20 years, was able to answer all carbohydrate questions correctly. The survey recognizes the need for ongoing education regarding diabetes management, even for those who present for other reasons to an ED.

It is interesting to note, there was no difference in carbohydrate knowledge based upon insulin use or years as a diabetic. $\mathrm{CC}$ has been considered the gold standard for mealtime adjustment of insulin dose for type 1 diabetics. ${ }^{[15,26]}$ This practice of CC ranges from an awareness of carbohydrate foods 
and its effects on insulin levels to counting of carbohydrate grams or portion size consumed. ${ }^{[26]}$ While some systematic reviews call into question the utility of $\mathrm{CC}$ in type 1 diabetics on factors such as glycemic control, weight, psychosocial factors, others suggests $\mathrm{CC}$ as beneficial for both type 1 and 2 diabetics. ${ }^{[9,11,15,27]}$ Although medical management may not change based on blood sugar or CC in Type 2 diabetes, it is an important tool to manage their blood sugars. As the disease progresses, even type 2 diabetics may need insulin therapy. ${ }^{[11]}$

Regarding DSME, studies have shown improved outcomes such as decreasing $\mathrm{Hb} \mathrm{A} 1 \mathrm{c}$ level, receiving care within recommended guidelines, and adhering to prescription regimens leading to lower utilization trends. ${ }^{[16,18,28,29]}$ Still, only $56.7 \%$ of Missouri diabetics have ever attended a DSME class, which is below the Healthy People 2020 goal of $62.5 \% .{ }^{[1]}$ Our results also suggest that those who visit with a nutritionist or diabetes educator have more knowledge to manage their diabetes. DSME begins with a diagnosis from a primary care provider, yet $28 \%$ of patients diagnosed with diabetes have no provider. ${ }^{[30]}$ A recent randomized controlled trial by Lewis et al. concluded that learner-centered DSME presented in the ED can be effective with uncontrolled type 2 diabetic patients. ${ }^{[30]}$ Other innovative techniques such as automated mobile health programs have been developed to help bridge the gap of underserved diabetic populations. ${ }^{[31,32]}$ Arora et al. found that while text messages did not statistically improve $\mathrm{Hb} \mathrm{A} 1 \mathrm{c}$, it did improve medication adherence, and healthy behaviors. ${ }^{[31,32]}$

This study supports the need for continued education from experienced providers who understand the complexities of diabetes management, in addition to other innovative techniques. Patients who may have even visited a nutritionist as part of their disease management have difficulty recalling $\mathrm{CC}$ and normal levels of blood sugar and A1c levels. An additional checkbox and process in the electronic health record to identify diabetic patients who need additional education prior to ED or hospital discharge, or referral to available outpatient DSME, may be helpful. Additional research is needed to evaluate the feasibility and effectiveness of starting DSME for patients who present to the ED.

\section{Conclunsions}

Carbohydrate knowledge and other self-care behaviors have been shown to be important in the self-management of diabetes. There is a vast deficit in carbohydrate knowledge in the diabetic ED population at this institution. There is a need for additional diabetes education whether started in the ED, or a referral to existing programs.

\section{ACKNOWLEDGeMENTS}

We would like to acknowledge Sarah Ghebrendrias, MD for her efforts in this study's development.

\section{CONFLicts OF INTEREST Disclosure}

\section{REFERENCES}

[1] Centers for Disease Control and Prevention. National Diabetes Statistics Report, 2014. Atlanta, GA: U.S. Department of Health and Human Services, Centers for Disease Control and Prevention, 2014.

[2] Washington R, Andrews R, Mutter R. Emergency Department visits for adults with diabetes. 2010. HCUP Statistical brief 167.

[3] Asao K, Kaminski J, McEwen LN, et al. Assessing the burden of diabetes mellitus in emergency departments in the United States: the National Hospital Ambulatory Medical Care Survey (NHAMCS). J Diabetes Complications. 2014 Sep-Oct; 28(5): 639-45. PMid: 24680472. https://doi.org/10.1016/j.jdiacomp. 2014.02.005

[4] Menchine MD, Arora S, Camargo CA, et al. Prevalence of undiagnosed and suboptimally controlled diabetes by point-of-care $\mathrm{HbA} 1 \mathrm{C}$ in unselected emergency department patients. Acad Emerg Med. 2011 Mar; 18(3): 326-9. PMid: 21362098. https ://doi.org/10.111 $1 / \mathrm{j} .1553-2712.2011 .01014 . \mathrm{x}$

[5] The effect of intensive therapy of diabetes on the development and progression of long-term complications in insulin-dependent diabetes mellitus: the Diabetes Control and Complications Trial Research Group. N Engl J Med. 1993; 329(14): 977-986. PMid: 8366922. https://doi.org/10.1056/NEJM199309303291401
[6] Fullerton B, Jeitler K, Seitz M, et al. Intensive glucose control versus conventional glucose control for type 1 diabetes mellitus. Cochrane Database Syst Rev. 2014 Feb; 14(2): CD009122. https : //doi.org/10.1002/14651858.cd009122.pub2

[7] Singh A, Donnino R, Weintraub H, et al. Effect of strict glycemic control in patients with diabetes mellitus on frequency of macrovascular events. Am J Cardiol. 2013 Oct 1; 112(7): 1033-8. PMid: 23768455. https://doi.org/10.1016/j.amjcard.2013.05.044

[8] Bell KJ, Barclay AW, Petocz P, et al. Efficacy of carbohydrate counting in type 1 diabetes: a systematic review and meta-analysis. Lancet Diabetes Endocrinol. 2014 Feb; 2(2): 133-40. https://doi.org/ 10.1016/S2213-8587(13) 70144-X

[9] Fu S, Li L, Deng S, et al. Effectiveness of advanced carbohydrate counting in type 1 diabetes mellitus: a systematic review and meta-analysis. Sci Rep. 2016; 6: 37067. PMid: 27841330. https://doi.org/10.1038/srep37067

[10] Goksen D, Altinok YA, Ozen S, et al. Effects of carbohydrate counting method on metabolic control in children with type 1 diabetes mellitus. J Clin Res Pediatr Endocrinol. 2014; 6(2): 74-8. https://doi.org/10.4274/jcrpe.1191

[11] Bowen ME, Cavanaugh KL, Wolff K, et al. The diabetes nutrition education study randomized controlled trial: A comparative effective- 
ness study of approaches to nutrition in diabetes self-management education. Patient Educ Couns. 2016 Aug; 99(8): 1368-76. PMid: 27026388. https://doi.org/10.1016/j.pec.2016.03.017

[12] Watts SA, Stevenson C, Adams M. Improving health literacy in patients with diabetes. Nursing. 2017 Jan; 47(1): 24-31. PMid: 27922896. https://doi.org/10.1097/01. NURSE. 000051073 9.60928.a9

[13] Swavely D, Vorderstrasse A, Maldonado E, et al. Implementation and evaluation of a low health literacy and culturally sensitive diabetes education program. J Healthc Qual. 2014 Nov; 36(6): 16-23. https://doi.org/10.1111/jhq.12021

[14] McCleary-Jones V. Health literacy and its association with diabetes knowledge, self-efficacy and disease self-management among African Americans with diabetes mellitus. ABNF J. 2011; 22(2): 25-32. PMid: 21675666

[15] Martins MR, Ambrosio AC, Nery M, et al. Assessment guidance of carbohydrate counting method in patients with type 2 diabetes mellitus. Prim Care Diabetes. 2014 Apr; 8(1): 39-42. PMid: 23702239. https://doi.org/10.1016/j.pcd.2013.04.009

[16] Chrvala CA, Sherr D, Lipman RD. Diabetes self-management education for adults with type 2 diabetes mellitus: A systematic review of the effect on glycemic control. Patient Educ Couns. 2016 Jun; 99(6): 926-43. PMid: 26658704. https://doi.org/10.1016/j. pec. 2015.11.003

[17] Haas L, Maryniuk M, Beck J, et al. National standards for diabetes self-management education and support. Diabetes Care. 2013 Jan; 36 Suppl 1: S100-8. PMid: 23264420. https ://doi.org/10.233 7/dc13-S100

[18] Powers MA, Bardsley J, Cypress M, et al. Diabetes Self-management Education and Support in Type 2 Diabetes: A Joint Position Statement of the American Diabetes Association, the American Association of Diabetes Educators, and the Academy of Nutrition and Dietetics. Diabetes Care. 2015 Jul; 38(7): 1372-82. PMid: 26048904. https://doi.org/10.2337/dc15-0730

[19] Li R, Shrestha SS, Lipman R, et al. Diabetes self-management education and training among privately insured persons with newly diagnosed diabetes-United States, 2011-2012. MMWR Morb Mortal Wkly Rep. 2014 Nov 21; 63(46): 1045-9. PMid: 25412060.

[20] US Census Bureau. American Community Survey Table S1701: Poverty status in past 12 months - 2011 American Community Survey 1 year estimates" for St. Louis City. February 8, 2016. [accessed: Preeti Dalawari] Available from: http://factfinder.census. gov

[21] Missouri HealthNet Division and the Department of Health and Senior Services. Missouri Diabetes Report. 2015. Available from: http: //health.mo.gov/living/healthcondiseases/chronic/c hronicdisease/MissouriDiabetesReport2015.pdf6

[22] Jeppesen KM, Hull BP, Raines M, et al. A validation study of the spoken knowledge in low literacy in diabetes scale (SKILLD). J Gen Intern Med. 2012 Feb; 27(2): 207-12. PMid: 22005940 https://doi.org/10.1007/s11606-011-1900-9

[23] Herndon JB, Chaney M, Carden D. Health literacy and emergency department outcomes: a systematic review. Ann Emerg Med. 2011 Apr 5; 7(4): 334-45.

[24] Olives T, Patel R, Patel S, et al. Health literacy of adults presenting to an urban ED. Am J Emerg Med. 2011 Oct; 29(8): 875-82.

[25] Sayah FA, Majumdar SR, Egede LE, et al. Measurement properties and comparative performance of health literacy screening questions in a predominantly low income African American population with diabetes. Patient education and counseling. 2014 Oct; 97(1): 88-95. https://doi.org/10.1016/j.pec.2014.07.008

[26] Bell KJ, Barclay AW, Petocz P, et al. Efficacy of carbohydrate counting in type 1 diabetes: a systematic review and meta-analysis. Lancet Diabetes Endocrinol. 2014 Feb; 2(2): 133-40. https ://doi .org/ 10.1016/S2213-8587 (13) 70144-X

[27] Schmidt S, Schelde B, Norgaard K. Effects of advanced carbohydrate counting in patients with type 1 diabetes: a systematic review. Diabet Med. 2014 Aug; 31(8): 886-96. PMid: 24654856. https://doi.org/10.1111/dme.12446

[28] Arora S, Marzec K, Gates C, et al. Diabetes knowledge in predominantly Latino patients and family caregivers in an urban emergency department. Ethn Dis. 2011; 21(1): 1-6. PMid: 21462722.

[29] Duncan I, Ahmed T, Li QE, et al. Assessing the value of the diabetes educator. Diabetes Educ. 2011 Aug; 37(5): 638-57. PMid: 21878591 https://doi.org/10.1177/0145721711416256

[30] Lewis V, Benda N, Nassar C, et al. Successful patient diabetes education in the emergency department. The Diabetes Educator. 2015 Jun; 41(3): 343-350. PMid: 25804628. https://doi.org/10.1177/ 0145721715577484

[31] Arora S, Peters AL, Burner E, et al. Trial to examine text messagebased mHealth in emergency department patients with diabetes (TExT-MED): a randomized controlled trial. Ann Emerg Med. 2014 Jun; 63(6): 745-54. PMid: 24225332. https ://doi .org/10.101 6/j.annemergmed. 2013.10.012

[32] Arora S, Peters AL, Agy C, et al. A mobile health intervention for inner city patients with poorly controlled diabetes: proof-of-concept of the TExT-MED program. Diabetes Technol Ther. 2012 Jun; 14(6): 492-6. PMid: 22524591. https ://doi.org/10.1089/dia.2011 .0252 